\title{
SOME APPLICATIONS OF BALLISTIC ELECTRON EMISSION MICROSCOPY/SPECTROSCOPY
}

\author{
J. WALACHOVÁ \\ Institute of Radio Engineering and Electronics \\ Chaberská 57, 18251 Praha 8, Czech Republic
}

\begin{abstract}
A brief review of ballistic electron emission microscopy and spectroscopy applications is presented. Results of our ballistic electron emission spectroscopy measurements on cleaved $n$-GaAs are given. The threshold in ballistic current-voltage characteristic is observed at bias $1.93 \mathrm{~V}$ which is high above the expected threshold. Explanation of this effect is given in the frame of present theoretical results.
\end{abstract}

PACS numbers: 73.20.Dx, 73.30.+y, 73.20.At

\section{Introduction}

The first description of ballistic electron emission microscopy (BEEM) methods was published by Kaiser and Bell in 1988 [1]. BEEM method is based on scanning tunneling microscopy (STM) measurement where the studied surface of semiconductor sample is covered with very thin layer of metal. Measurements are taken with constant tunneling current $I_{\mathrm{t}}$ between scanning tip and metal layer. Some tunneling electrons can cross ballistically the metal layer and the net ballistic current $I_{\mathrm{c}}$ in the range of $\mathrm{pA}$ is collected in the back contact of the semiconductor. The current $I_{c}$ is imaged simultaneously with topography of the sample during scanning of the tip at constant bias $V$ between the tip and sample. In spectroscopic measurements (BEES) the ballistic current-voltage $\left(I_{\mathrm{c}}-V\right)$ characteristics are measured at individual points of the sample, where $V$ is the bias between tip and metal layer. Because metal layer forms a Schottky barrier $\Phi_{\mathrm{b}}$ with the semiconductor the $I_{\mathrm{c}}$ begins to increase significantly when ballistic electrons can flow over the Schottky barrier. It occurs at bias $V>V_{\text {th }}=\Phi_{\mathrm{b}} / e$ where $V_{\text {th }}$ is threshold bias. Near $V_{\text {th }}$ the $I_{\mathrm{c}}=T\left(V-V_{\mathrm{th}}\right)^{\alpha}$, where $T$ is transmission scaling factor and $\alpha$ is a value between 1 and $9 / 2$. When fitting $V_{\text {th }}$ and $T$ to experimental $I_{\mathrm{c}}-V$, the $\Phi_{\mathrm{b}}$ can be determined. The value of $\alpha$ which gives the best fitting to experimental data depends on the validity of many assumptions for tunneling current distribution, transport through the metal film, transmission across the interface, and transport in the semiconductor. Usually only low cone of ballistic electrons can enter the semiconductor because of the conservation of transverse momentum 
law and the lateral resolution of BEEM method can be as high as 1-2 nm. The detailed review on this subject could be found in [2]. But transport of electrons in BEEM is still under question [3-5].

\section{The brief review of BEEM/BEES applications}

The most common application of BEEM/BEES is connected with the study and measurement of the Schottky barrier height on such semiconductors as $\mathrm{Si}$, $\mathrm{GaAs}, \mathrm{GaP}, \mathrm{CdTe}, \mathrm{ZnSe}$. Usually $n$-type semiconductors are studied but study on $p$-type is possible as well $[6,7]$. Schottky barrier height can be determined with nanometer special resolution [8] and with precision as high as $0.02 \mathrm{eV}$ [9]. Influence of different methods of preparation of Schottky barriers can be studied (nearly ideal barriers prepared in situ in UHV [10], barriers with thin native oxide between metal and semiconductor [11], barriers prepared on RF plasma cleaned semiconductor surface [12] on reactive ion etched surface [13] and on mechanically polished surface [14]). Influence of semiconductor surface orientation is investigated [15-18]. Epitaxially grown Schottky barriers are very frequently studied because of their very ordered interface $\left(\mathrm{PtSi} / \mathrm{Si}\right.$ [19], NiSi/Si [20-22], $\mathrm{CoSi}_{2} / \mathrm{Si}$ [15-18, 23-25], CoGa/GaAs [26]). Schottky barrier homogeneity is one of the most important studied problems [11,27,28], because of future nanometer dimension devices fabrication. BEES measurements on Schottky barriers give information about the band structure at the subsurface interface [29] and also energy of the higher laying minima in the band structure can be determined [26, 30, 31]. The density of state effects in the semiconductor can be observed [31]. The reverse BEES spectra can be studied [22]. BEEM images, usually correlated with topography give important information about structural defects at the interfaces of Schottky barriers [20, 21, 32-34]. The interfacial dislocation can be observed in BEEM pictures [23, 24] and microclusters of different phases [35]. The Schottky barrier height can be correlated with defects and with topography of metal surface [32-34]. Direct imaging with nanometer scale of the Schottky barrier height is possible [28]. On epitaxially grown Schottky barriers the periodic surface structure can be imaged with atomic resolution by BEEM $[17,18]$ and the study of this effect give useful information about tunneling process on an atomic scale [36].

BEEM and BEES give important information about transport properties, about elastic and inelastic scattering [37], conservation of transverse momentum [38], and spacial resolution in the sample. Quantitative agreement of measured results with calculated ones is possible [39].

Reverse biased Shottky barriers can be studied [40].

For many applications the low temperature measurements are necessary $[7,23,41,42]$ using modulation spectroscopy [25, 43]. Very useful is also BEEM measurement at constant height mode [44].

BEEM and BEES are applicable for study of more complicated structures than Schottky barriers. On InAs/GaAs there was studied lateral resolution of band offsets and influence of misfit dislocations on band offsets homogeneity [45]. Band offsets were also studied on $\mathrm{Al}_{x} \mathrm{Ga}_{1-x} \mathrm{As} / \mathrm{GaAs}$ [46] and GaInP/GaAs [47]. The height of the buried AlAs barrier was studied on strained and relaxed $\mathrm{In}_{0.35} \mathrm{Ga}_{0.65} \mathrm{As} / \mathrm{AlAs}$ heterojunction [48]. In double barrier resonant tunneling het- 
erostructures the quasi-bound states in the well can be detected $[49,50]$. The $\mathrm{Pt}-\mathrm{SiO}_{2}-\mathrm{Si}$ structures can be studied [51] and the trapped charge in $\mathrm{SiO}_{2}$ can be detected with high sensitivity [52]. It was found that density of states in the gap of $\mathrm{CaF}_{2}$ influence electron transport through the interlayers of $\mathrm{Au}-\mathrm{CaF}_{2}-\mathrm{Si}$ structure and can be detected by BEES [53].

The GaAs $/ \mathrm{Al}_{x} \mathrm{Ga}_{1-x}$ As quantum wires were detected by BEEM on laterally structured sample $[54,55]$ as well as buried lateral period AlAs/GaAs superlattice [56].

As the last application, we mention the possible permanent modification of local ballistic transmittance of metal/semiconductor interfaces in BEEM at higher voltages which allows to store and reread information [57-60].

\section{BEES measurement on (110) cleaved $n$-GaAs}

Although many publications deal with BEEM/BEES study on differently oriented samples there was no study by BEEM/BEES of (110) cleaved GaAs.

We study $n$-GaAs samples grown in (100) direction with concentration of donors $2 \times 10^{18} \mathrm{~cm}^{-3}$. The slide of this material was cleaved along the (110) plane at UHV condition and $10 \mathrm{~nm}$ Au layer was evaporated in situ on cleaved surface. The sample was then removed from UHV and installed to STM. The back contact was made by silver paste and the contact to $\mathrm{Au}$ layer was made by fine $\mathrm{Ag}$ wire spring. The sketch of BEEM experimental configuration is shown in Fig. 1. The sample is biased during measurement. The ballistic current $I_{\mathrm{c}}$ is measured between $\mathrm{Au}$ contact and back contact by flowing picoammeter for different bias $V$ between tip and Au layer at constant tip current $I_{\mathrm{t}} . I_{\mathrm{c}} / I_{\mathrm{t}}-V$ characteristics are measured in the bias range from $0.5 \mathrm{~V}$ to $2.3 \mathrm{~V}$. The resulting characteristic at measured place (point) is an average of 20 characteristics. The step in measured characteristic is $0.01 \mathrm{~V}$ and at each step the $I_{\mathrm{c}}$ is an average of 2000 measured values. The surface about $20 \times 20 \mathrm{~nm}^{2}$ is examined at equidistant points. The BEES measurements are correlated with topography images of the sample. The distance between individual points, where the BEES measurement is made is $2 \mathrm{~nm}$. The threshold voltages are determined from linear part of $\left(I_{\mathrm{c}} / I_{\mathrm{t}}\right)^{1 / 2}-V$ characteristics.

We observed at all studied samples the thresholds above the threshold attributes to expected Schottky barrier height or two groups of thresholds from

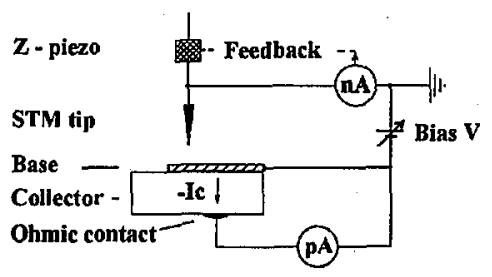

Fig. 1. Sketch of BEEM experimental configuration. 
which one is below and one above the expected Schottky barrier height [61]. On the base of later experiments we find definitely that this effect is not the effect of the tip contamination as we suppose in [61]. We observe that the effect depends on the number and height of the steps at the cleaved surface. The details of this study will be published later elsewhere. Here we present results obtained on very smooth cleaved surface with step observed in studied region.

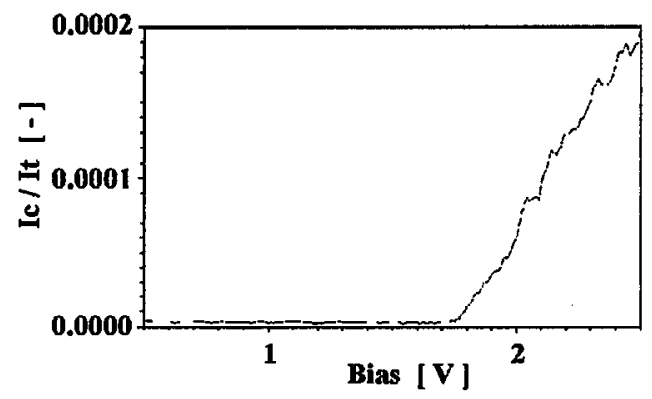

Fig. 2. Typical $I_{c} / I_{t}-V$ (BEES) characteristic of smooth (110) cleaved $n$-GaAs surface covered with $10 \mathrm{~nm}$ of Au.

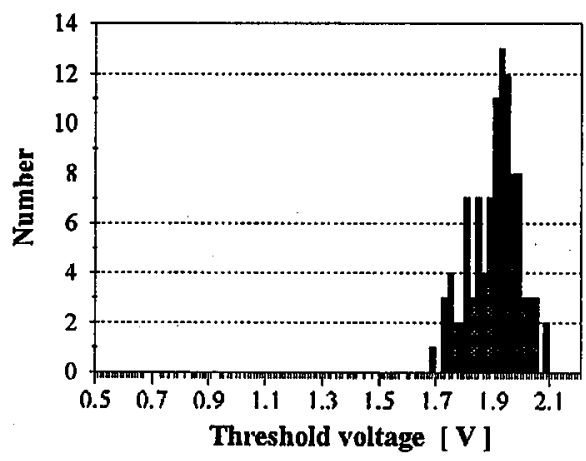

Fig. 3. Distribution of values of threshold in $I_{c} / I_{t}-V$ characteristics measured by BEES on smooth (110) cleaved $n$-GaAs surface covered with $10 \mathrm{~nm}$ of $\mathrm{Au}$.

Typical $I_{\mathrm{c}} / I_{\mathrm{t}}-V$ characteristic of such sample is shown in Fig. 2. The tunneling current $I_{\mathrm{t}}$ was held constant and it was $10 \mathrm{nA}$. The characteristics show threshold about $1.93 \mathrm{~V}$. The distribution of values of measured thresholds is shown in Fig. 3. The maximum of distribution is high above the expected value. Usually measured Schottky barrier height on Au- $n$ GaAs is about $0.9 \mathrm{eV}$ and for our highly doped material it is expected that the Schottky barrier height is lowered by effect of tunneling and by imàge force effect. Therefore we conclude that there is no observable transport of electrons to the conduction band minimum $\Gamma$ of GaAs in our samples. The observed threshold cannot be connected with transport to higher 
laying $L$ and $X$ bulk conduction band minima which are 0.29 and 0.46 above the $\Gamma$ conduction band minima of GaAs [26, 62]. If we examine the projected bulk band structure of GaAs at (110) direction [63] we find that there exists the very weak minimum near $\bar{X}$ point of the surface Brillouin zone. This minimum is about $1.35 \mathrm{eV}$ above $\Gamma$ conduction band minimum of GaAs. If we subtract this value from the measured threshold $1.93 \mathrm{~V}$ we obtain the value $0.58 \mathrm{eV}$. It is in good agreement with expected value of the Schottky barrier height for $n$-GaAs with concentration of donors about twice as higher $\left(4 \times 10^{18} \mathrm{~cm}^{-3}\right)$ as was measured for our material $\left(2 \times 10^{18} \mathrm{~cm}^{-3}\right)$. This discrepancy is probably caused by the creation of defects during cleaving, even the surface looks quite perfect.

The open question is why ballistic electron transport to $\Gamma, X$ and $L$ minima is practically excluded. One possible explanation is that the minimum in projected bulk band structure near $\bar{X}$ point of the surface Brillouin zone [63] is connected with very high effective mass of electrons and this is the reason why acceptance angle for ballistic electrons is much higher for these minima than for the other minima [29]. The other explanation is that electrons during transport through the Au layer can be focused along specific directions [3] and that some of this directions coincide with the position of minima $1.35 \mathrm{eV}$ above $\Gamma$ minima in the projected bulk band structure of GaAs in (110) direction. Most probably both effects mentioned above contribute to the preferential transport of electrons to weak minima $1.35 \mathrm{eV}$ above the $\Gamma$ minima.

\section{Conclusion}

Although many works in BEEM/BEES concern the study of transport of electrons, the problem is still open and new results can be expected. Our experimental results on Au- $n \mathrm{GaAs}$ (110) cleaved sample fully support this fact. The further BEEM/BEES experimental and theoretical works will be useful mainly on Schottky barriers on samples with different orientation and with different thickness of the metal layer.

In the end I thank J. Vaniš for help with manuscript preparation, J. Zelinka and S. Karamazov for BEEM/BEES hardware and software realization, M. Cukr and P. Zich for help with samples preparation and L. Jezierska for Pt tip preparation.

This work was supported by Czech Grant Agency project 102/97/0427.

\section{References}

[1] W.J. Kaiser, L.D. Bell, Phys. Rev. Lett. 60, 1406 (1988).

[2] M. Prietsch, Phys. Rep. 253, 163 (1995).

[3] F.J. Garcia-Vidal, P.L. de Andres, F. Flores, Phys. Rev. Lett. 76, 807 (1996).

[4] C.A. Ventrice, Jr., V.P. La Bella, G. Ramaswamy, H.-P. Yu, L.J. Showalter, Phys. Rev. B 53, 3952 (1996-I).

[5] L.D. Bell, Phys. Rev. Lett. 77, 3893 (1996).

[6] L.D. Bell, W.J. Kaiser, M.H. Hecht, I.C. Davis, J. Vac. Sci. Technol. B 9, 94 (1991). 
[7] L.D. Bell, S.J. Manion, M.H. Hecht, W.J. Kaiser, R.W. Fathauer, A.M. Milliken, Phys. Rev. B 48, 5712 (1993).

[8] L.D. Bell, W.J. Kaiser, Scanning Microsc. 2, 1231 (1988).

[9] R. Ludeke, M. Prietsch, A. Samsovar, J. Vac. Sci. Technol. B 9, 2342 (1991).

[10] J.W. Kaiser, L.D. Bell, M.H. Hecht, F.J. Grunthaner, J. Vac. Sci. Technol. B 7, 945 (1989).

[11] A.A. Talin, D.A.A. Ohlberg, R.S. Williams, P. Sullivan, I. Koutselas, B. Williams, K.L. Kavanagh, Appl. Phys. Lett. 62, 2965 (1993).

[12] L. Quattropani, K. Solt, P. Niedermann, I. Magio-Aprile, $\varnothing$. Fischer, I. Pavelka, Appl. Surf. Sci. 70-71, 391 (1993).

[13] A. Davies, J.G. Couillard, H.G. Craighead, Appl. Phys. Lett. 61, 1040 (1992).

[14] J.I. Everaert, R.L. Van Meirhaeghe, W.M. Laflére, F. Cardon, Semicond. Sci. Technol. 10, 504 (1995).

[15] Fl. Sirringhaus, E.Y. Lee, V. Kafader, H. von Känel, J. Vac. Sci. Technol. B 13, 1848 (1995).

[16] E.Y. Lee, H. Sirringhaus, V. Kafader, H. von Känel, Phys. Rev. B 52, 1816 (1995).

[17] H. Sirringhaus, E.Y. Lee, H. von Känel, Surf. Sci. 331-333, 1277 (1995).

[18] H. Sirringhaus, E.Y. Lee, H. von Känel, Phys. Rev. Lett. 74, 3999 (1995).

[19] P. Niedermann, L. Quattropani, K. Solt, A.D. Kent, $\varnothing$. Fischer, J. Vac. Sci. Technol. 10, 580 (1992).

[20] A. Fernandez, H.D. Hallen, T. Huang, R.A. Buhrman, J. Silcox, Phys. Rev. B 44, 3428 (1991).

[21] H.D. Hallen, A. Fernandez, T. Huang, J. Silcox, R.A. Buhrman, Phys. Rev. B 46, 7256 (1992).

[22] P. Niedermann, L. Quattropani, K. Solt, I. Maggio-Aprile, $\varnothing$. Fischer, Phys. Rev. $B$ 48, 8833 (1993).

[23] H. Sirringhaus, E.Y. Lee, H. von Känel, Phys. Rev. Lett. 73, 577 (1994).

[24] H. Sirringhaus, E.Y. Lee, H. von Känel, J. Vac. Sci. Technol. B 12, 2629 (1994).

[25] H. Sirringhaus, E.Y. Lee, H. von Känel, Phys. Rev. B 50, 14714 (1994).

[26] L. Tsau, T.C. Kuo, K.L. Wang, Appl. Phys. Lett. 63, 1062 (1993).

[27] A.E. Fowell, R.H. Williams, B.E. Richardson, T.H.Shen, Semicond. Sci. Technol. 5, $348(1990)$.

[28] H. Palm, M. Arbes, M. Schulz, Appl. Phys. A 56, 1 (1993).

[29] L.D. Bell, W.J. Kaiser, Phys. Rev. Lett. 61, 2368 (1988).

[30] A.E. Fowell, R.H. Williams, B.E. Richardson, A.A. Cofolla, D.I. Westwood, D.A. Woolf, J. Vac. Sci. Technol. B 9, 581 (1991).

[31] R. Ludeke, J. Vac. Sci. Technol. A 11, 786 (1993).

[32] M.H. Hecht, L.D. Bell, W.J. Kaiser, Appl. Surf. Sci. 41-42, 17 (1989).

[33] M.H. Hecht, L.D. Bell, W.J. Kaiser, F.J. Grunthaner, Appl. Phys. Lett. 55, 780 (1989). 
[34] M. Prietsch, R. Ludeke, Phys. Rev. Lett. 66, 2511 (1991).

[35] R. Coratger, F. Ajustron, J. Beauvillain, I.M. Dharmadasa, C.J. Blomfield, K.A. Prior, J. Simpson, B.C. Cavenett, Phys. Rev. B 51, 2357 (1995).

[36] H. Sirringhaus, T. Meyer, E.Y. Lee, H. von Känel, Surf. Sci. 357-358, 386 (1996).

[37] L.D. Bell, M.H. Hecht, W.J. Kaiser, I.C. Davis, Phys. Rev. Lett. 64, 2679 (1990).

[38] L.J. Schowalter, E.Y. Lee, Phys. Rev. B 43, 9308 (1991).

[39] A. Bauer, M.T. Cuberes, M. Prietsch, G. Kaindl, Phys. Rev. Lett. 71, 149 (1993).

[40] A. Davies, H.G. Craighead, Appl. Phys. Lett. 64, 2833 (1994).

[41] G.N. Henderson, P.N. First, T.K. Gaylord, E.N. Glytsis, Phys. Rev. Lett. 71, 2999 (1993).

[42] C.A. Ventrice, Jr., V.P. La Bella, G. Ramaswamy, H.-P. Yu, L.J. Schowalter, Appl. Surf. Sci. 104-105, 274 (1996).

[43] E.Y. Lee, B.R. Turner, L.J. Schowalter, J.R. Jimenez, J. Vac. Sci. Technol. B 11, 1579 (1993).

[44] E.Y. Lee, H. Sirringhaus, H. von Känel, Surf. Sci. 314, 1825 (1994).

[45] T.-H. Shen, M. Elliott, A.E. Fowell, A.A. Cofolla, B.E. Richardson, D.I. Westwood, R.H. Williams, J. Vac. Sci. Technol. B 9, 2219 (1991).

[46] J.J. O'Shea, T. Satojo, S. Bhargava, D. Leonard, M.A. Chin, V. Narayanamurti, J. Vac. Sci. Technol. B 12, 2625 (1994).

[47] J.J. O'Shea, C.M. Reaves, S.P. Den Baars, M.A. Chin, V. Narayanamurti, Appl. Phys. Lett. 69, 3022 (1996).

[48] Mao-long Ke, D.I. Westwood, S. Wilks, S. Heghoyan, A.Kestle, C.C. Matthai, B.E. Richardson, R.H. Williams, J. Vac. Sci. Technol. B 13, 1684 (1995).

[49] T. Satojo, J.J. O'Shea, S. Bhargava, D. Leonard, M.A. Chin, V. Narayanamurti, Phys. Rev. Lett. 74, 3427 (1995).

[50] J. Walachová , J. Zelinka, J. Vaniš, D.H. Chow, J.N. Schulman, S. Karamazov, M. Cukr, P. Zich, J. Král, T.C. McGill, Appl. Phys. Lett. 70, 3588 (1997).

[51] R. Ludeke, A. Bauer, E. Cartier, J. Vac. Sci. Technol. B 13, 1830 (1995).

[52] B. Kaczer, Z. Meng, J.P. Pelz, Phys. Rev. Lett. 77, 91 (1996).

[53] M.T. Cuberes, A. Bauer, H.J. Wen, M. Prietsch, G. Kaindl, J. Vac. Sci. Technol. $B$ 12, 2646 (1994).

[54] C. Eder, J. Smoliner, G. Strasser, E. Gornik, Superlattices Microstruct. 20, 357 (1996).

[55] C. Eder, J. Smoliner, G. Strasser, E. Gornik, Appl. Phys. Lett. 69, 1725 (1996).

[56] D.I. Westwood, Mao-long Ke, F. Lelarge, F. Laruelle, B. Etienne, Surf. Sci. 352-354, 802 (1996).

[57] R. Ludeke, A.B. McLean, Taleb-Ibrahimi, Phys. Rev. B 42, 2982 (1990).

[58] H.D. Hallen, A. Fernandez, T. Huang, R.A. Buhrman, J. Silcox, J. Vac. Sci. Technol. B 9, 585 (1991).

[59] A. Fernandez, H.D. Hallen, T. Huang, R.A. Buhrman, J. Silcox, Appl. Phys. Lett. 57, 2826 (1990). 
[60] H.D. Hallen, T. Huang, A. Fernandez, J. Silcox, R.A. Buhrman, Phys. Rev. Lett. 69, 2931 (1992).

[61] S. Karamazov, J. Walachová, J. Zelinka, J. Vaniš, M. Cukr, P. Zich, in: Abstracts of Contributed Papers, EPS 10 Trends in Physics, EPS, Sevilla 1996, p. 37.

[62] Mao-long Ke, D.I. Westwood, C.C. Matthai, B.E. Richardson, R.H. Williams, Phys. Rev. B 53, 4845 (1996).

[63] I. Ivanov, A. Mazur, J. Pollmann, Surf. Sci. 92, 365 (1980). 